\title{
Simple platelet markers: Mean platelet volume and congestive heart failure coexistent with periodontal disease. Pilot studies
}

\author{
Maciej R. Czerniuk ${ }^{1}$, Zbigniew Bartoszewicz ${ }^{2}$, Iwona Dudzik-Niewiadomska ${ }^{3}$, \\ Tomasz Pilecki ${ }^{4}$, Renata Górska ${ }^{1}$, Krzysztof J. Filipiak ${ }^{5}$ \\ ${ }^{1}$ Department of Oral Medicine and Periodontal Disease, Medical University of Warsaw, Poland \\ ${ }^{2}$ Endocrinology Laboratory, Department of Internal Diseases and Endocrinology, \\ Medical University of Warsaw, Poland \\ ${ }^{3}$ Department of Internal Medicine and Cardiology with the Center of Management \\ of Thromboembolic Disease, Medical University of Warsaw, Poland \\ ${ }^{4}$ Department of Immunology, Transplantology and Internal Diseases, Medical University of Warsaw, Poland \\ ${ }^{5}$ First Chair and Department of Cardiology, Medical University of Warsaw, Poland
}

\begin{abstract}
Background: Conducted pilot study concerning mean platelet volume (MPV) parameter among patients suffering from congestive heart failure and periodontal disease.

Methods: Examination of dynamic changes of platelet and periodontal markers in group of 50 patients before and an average of 6 months subsequent to professional periodontal treatment.

Results: Both platelet and periodontal parameters decreased after periodontal treatment, what is more, the decrease of MPV value due to periodontal disease/mm improvement was shown to be statistically significant $(p=0.05)$.

Conclusions: Improvement of periodontal status may influence decrease of MPV value and increase of congestive heart failure treatment efficacy and effect patient comfort. It is a new, not frequently used pattern of chronic disease treatment optimalization. (Cardiol J 2019; 26, 3: 253-259)
\end{abstract}

Key words: mean platelet volume, platelets, congestive heart failure, periodontal disease, inflammatory response

\section{Introduction}

Numerous papers have documented prognostic value of mean platelet volume (MPV) in cardiovascular pathology [1-7], including published research on correlation between MPV and periodontal disease (PDe) in coronary patients [8]. A thorough search on correlation between MPV and exacerbated heart failure revealed only 2 publications in this area $[9,10]$. MPV has not yet been studied in patients with congestive heart failure (CHF), including those with coexistent PDe.
The aim of this study was to assess the dynamics of changes of MPV in CHF patients with diagnosis of PDe. The authors made an attempt to design a clinical pilot study that will verify the following hypotheses: (A) Is MPV an appropriate marker of periodontal parameters change the dynamics? Analyzed BEFORE periodontal intervention; (B) Is MPV an appropriate marker of periodontal parameters change the dynamics? Whether a clinical decrease of some periodontal parameters $(\mathrm{CAL} / \mathrm{mm}, \mathrm{PI}$, and $\mathrm{PD} / \mathrm{mm})$ may result in MPV? Analyzed AFTER periodontal intervention.

Address for correspondence: Maciej R. Czerniuk, DMD, MSc, PhD, Department of Oral Medicine and Periodontal Disease, Medical University of Warsaw, ul. Miodowa 18, 00-246 Warszawa, Poland, tel/fax: +48 22502 20 99, e-mail: mczerniuk@o2.pl 
There is a correlation between the decrease of inflammatory process presented by plasma concentration of the following parameters: tumor necrosis factor-alpha (TNF- $\alpha$ ), N-terminal pro-B-type natriuretic peptide (NT-proBNP), C-reactive protein (CRP) and improvement of $\mathrm{CHF}$ patient status, including better prognosis [11-17]. Numerous researchers have shown that elimination of inflammation in PDe results in a significant reduction of chronic inflammatory process and may lead to additional benefits including improvement of vascular endothelium [18-22].

\section{Methods}

A pilot group of 50 patients aged 36-92 years including 15 women and 35 men (average age 64 years), admitted to the Department of Cardiology of the Medical University of Warsaw with a diagnosis of CHF. Those patients were also diagnosed with PDe that required periodontal treatment.

This pilot study was conducted in accordance with 1964 Declaration of Helsinki and was approved by the Ethics Committee of the Medical University of Warsaw (KB/54/A/2013). All patients have read and signed informed consent forms.

After obtaining their consent, all patients enrolled in the study underwent the following diagnostic assessment:

- Biochemical blood tests on admission day and on average 6 months after periodontal treatment: blood count, iodine and potassium concentration, lipid profile, CRP and TNF- $\alpha$ levels, NT-proBNP and fibrinogen concentration.

- Examination of oral hygiene: approximal plaque index (API) inspected on approximal spaces of the first and third quadrants from the oral aspect and of the second and fourth quadrant from the buccal aspect and bleeding on probing (BOP) probed on 4 surfaces of each tooth (mesial, distal, platal/lingual, buccal) during initial standard periodontal therapeutic assessment (scaling, root-planing, sanitation of oral cavity as well as treatment of oral mucosa pathologies). Number and status of teeth, number and status of impacted teeth, gangrenous roots, currently used prosthetic restorations, as well as surgical and prosthetic treatment indications were assessed [23].

- Periodontal examination of clinical attachment loss $(\mathrm{CAL} / \mathrm{mm})$ and probing depth $(\mathrm{PD} /$ $/ \mathrm{mm}$ ) in oral cavity with the use of periodontal probe WHO 621 in 6 measurement points around each tooth (mesial buccal, distal buc- cal, middle of buccal surface, mesial palatal/ /lingual, distal palatal/lingual, middle of palatal/ /lingual surface) and dental orthopantomogram radiograph (OPG) in $\mathrm{CHF}$ patients following conventional periodontal therapy assessment: removal of bacterial biofilm from tooth surface (scaling) and smoothing (root-planing) to prevent re-accumulation of bacteria, sanitation of oral cavity as well as periodontal reassessment on average 6 months (3-9 months) after treatment.

Study patients were treated in accordance with current CHF treatment guidelines, without need of modifications of pharmacological therapy, and their clinical status was stable throughout the study. Based upon results of initial examination, pilot specialist periodontal treatment was commenced in patients with coexistent $\mathrm{CHF}$ and PDe in a reference clinical center.

This paper presents statistical analysis of a relationship between dynamic MPV changes in relation to PDe and oral hygiene status.

Blood samples were collected from all 50 study patients on admission day (examination-1), and then 3-9 months (on average 6 months) after periodontal treatment was completed (examination-2). Blood samples were centrifuged and serum was tested for blood count including diagnostic parameters of platelet count and volume, which were the subject of the study and were further analyzed. A standard blood work-up kit (R\&D Systems, Inc., Minneapolis, USA) was used in accordance with manufacturer instructions in the Central Laboratory Department of Hematology, Oncology and Internal Diseases of the Medical University of Warsaw.

The status of CHF was examined before and after periodontal therapy by two experienced cardiologists blinded to the periodontal therapy outcomes and indices.

The periodontal study was conducted at the Department of Oral Medicine and Periodontal Disease of the Medical University of Warsaw, with the use of periodontal probe WHO 621. During the examination antibiotics were administered prophylactically. All patients received Augmentin ${ }^{\circledast}$ (amoxicillinum, acidum clavulanicum) $1.0 \mathrm{~g}$ ( $1 \mathrm{~d} /$ every $12 \mathrm{~h})$, and for those with penicillin intolerance Dalacin $\mathrm{C}^{\otimes}$ (clindamycinum) $0.3 \mathrm{~g}(1 \mathrm{~d} /$ every $8 \mathrm{~h}$ ) was prescribed. For periodontal examination, patients received single, prophylactic dose (Augmentin ${ }^{\circledR}$ $-2 \mathrm{~g}$; Dalacin $\mathrm{C}^{\otimes}-0.6 \mathrm{~g}$ ) according to guidelines concerning examination of such patients issued by the Polish Society of Periodontology. API/\% and 
$\mathrm{BOP} / \%$ were assessed, scaling, root-planing and orthopantomogram radiograph were performed. Detailed instructions for daily oral hygiene were provided. The above described activities were termed as periodontal intervention.

Following periodontal assessment, also with antibiotic administration, examination of clinical attachment loss $(\mathrm{CAL} / \mathrm{mm})$ as well as probing depth $(\mathrm{PD} / \mathrm{mm}$ - probing depth), degree of furcation involvement, and 3-stage Hall's tooth mobility scale, where stage 1 represents lingual or buccal/palatal mobility, no more than $1 \mathrm{~mm}$; stage 2 - lingual or buccal/palatal mobility between 1 and $2 \mathrm{~mm}$; stage 3 - vertical and horizontal mobility that interrupts proper articulation was performed $[24,25]$. Each tooth was examined and mean parameters values were calculated for individual patients.

All patients received standard periodontal therapy: scaling and root planing with sanitation of oral cavity including extraction of gangrenous roots under antibiotic prophylaxis regimen. For periodontal treatment full antibiotic therapy was administered (Augmentin ${ }^{\circledR}-14$ doses/7 days; Dalacin $\mathrm{C}^{\circledast}-15$ doses/5 days) according to the same guidelines. Recommended oral hygiene at home includedbrushing teeth twice a day, in the morning and in the evening, as well as antiseptic mouth rinsing. Patients were encouraged to stay in touch with researchers in case of any doubts regarding their oral cavity status and hygiene routine.

\section{Statistical analysis}

Obtained results underwent statistical analysis in order to assess the influence of treatment on MPV with reference to selected periodontal parameters. Following statistical tests were performed to verify stated hypotheses.

Statistical analysis was performed with MannWhitney test for dependent groups to verify differences between observations and Wilcoxon test to assess differences between selected study groups (H.B. Mann, D.R. Whitney [1947] "On a test of whether one of two random variables is stochastically larger than the other". Annals of Mathematical Statistics, 18, 50-60).

\section{Results}

All patients were diagnosed with severe chronic generalized periodontitis (CAL $>5 \mathrm{~mm}$ and PD $>7 \mathrm{~mm}$ ) according to American Academy of Periodontology 2000 classification [26].

Pilot study of $50 \mathrm{CHF}$ patients with coexistent PDe on admission day has shown that mean

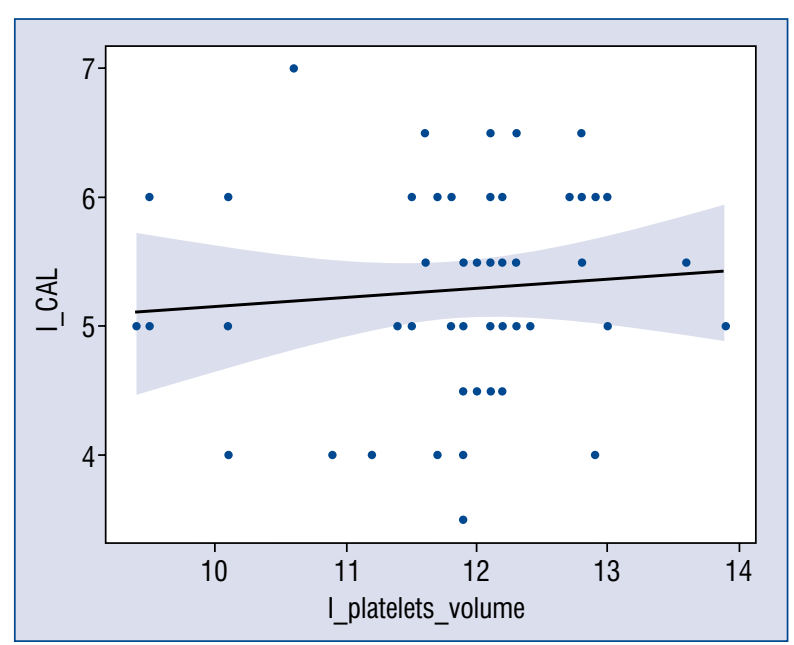

Figure 1. The values of mean platelet volume (MPV) vs. clinical attachment loss $(\mathrm{CAL} / \mathrm{mm})$ before periodontal intervention (MPV $\pm \mathrm{SD} 0.91 ; \mathrm{CAL} / \mathrm{mm} \pm \mathrm{SD} 0.39$ ); $\mathrm{SD}$ - standard deviation.

API and BOP values were very high, respectively: API: $74 \%$ in women and $81 \%$ in men; BOP: $100 \%$ in women and $90 \%$ in men. Mean $\mathrm{PD} / \mathrm{mm}$ values both for women and men were $5.7 \mathrm{~mm}$. Mean CAL/ $/ \mathrm{mm}$ values were $5.2 \mathrm{~mm}$ for women and $5.3 \mathrm{~mm}$ for men. Among women the average number of teeth in the upper arch was 12 and in lower arch -11 . In the group of men the average number of teeth in maxilla was 11 and in mandible -10 .

A. Study results show that as far as first hypothesis is concerned, patients before periodontal intervention, high values of MPV parameter have shown correlation with high values of the following parameters: $\mathrm{CAL} / \mathrm{mm}$, plaque index (PI) and $\mathrm{PD} / \mathrm{mm}$ obtained during the first assessment (examination-1).

\section{A.I. MPV vs. CAL/mm (examination-1)}

Statistical analysis has shown that higher MPV value is associated with higher $\mathrm{CAL} / \mathrm{mm}$ value. Presented model did not show statistically significant relationship. The numerical relationship was positive. The following results were obtained: statistical value W: 0.3694; p: 0.5462 (Fig. 1).

\section{A.II. MPV vs. PD/mm (examination-1)}

Statistical analysis has shown that $\mathrm{PD} / \mathrm{mm}$ values are subtle. In addition: although there is no clear trend in relationship between these parameters a positive trend is present, the highest MPV values are for patients with $\mathrm{PD} / \mathrm{mm} 7 \mathrm{~mm}$ (the highest) value obtained (Fig. 2). 


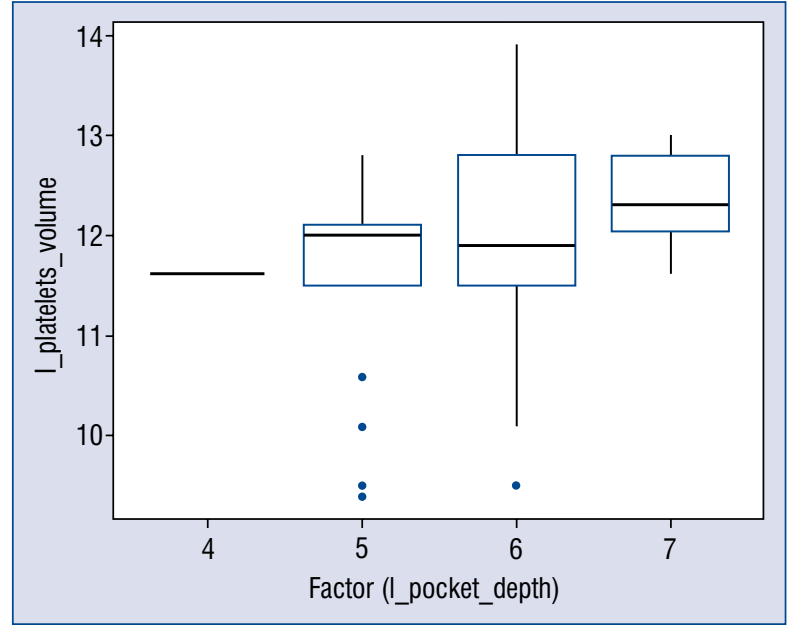

Figure 2. The values of mean platelet volume (MPV) vs. probing depth $(\mathrm{PD} / \mathrm{mm})$ before periodontal intervention (MPV \pm SD 0.91; PD/mm \pm SD 0.60); SD - standard deviation.

B. Study results show that as far as second hypothesis is concerned in patients after periodontal intervention high values of MPV parameter have shown correlation with high values of the following parameters: $\mathrm{CAL} / \mathrm{mm}, \mathrm{PI}$ and $\mathrm{PD} / \mathrm{mm}$, obtained during the second assessment (examination-2).

\section{B.I. $M P V$ vs. $C A L / m m$ (examination-2)}

Statistical analysis has shown that there is virtually no relationship between $\mathrm{CAL} / \mathrm{mm}$ and MPV value after periodontal intervention. The presented model did not show any statistically significant relationship. The following results were obtained: statistical value W: 0.03385; p: 0.8548 (Fig. 3).

\section{B.II. $M P V$ vs. PD/mm (examination-2)}

Statistical analysis has shown that $\mathrm{PD} / \mathrm{mm}$ values are subtle. In addition: there is a positive trend (higher $\mathrm{PD} / \mathrm{mm}$ is associated with higher MPV value), and the highest MPV values are for $\mathrm{PD} / \mathrm{mm} 5 \mathrm{~mm}$ (the highest) (Fig. 4).

\section{B.III. MPV change vs. CAL/mm change}

Assessment whether $\mathrm{CAL} / \mathrm{mm}$ parameters change observed before and after periodontal intervention is associated with MPV. For CAL $/ \mathrm{mm}$ change at $1.5 \mathrm{~mm} \mathrm{MPV}$ is higher and characterized with grater variability. Following results were obtained: statistical value W: 306.5; p: 0.3076 (Fig. 5).

Results show that this difference is not significant. It should be noted that for greater $\mathrm{CAL} / \mathrm{mm}$ change MPV distribution towards higher values

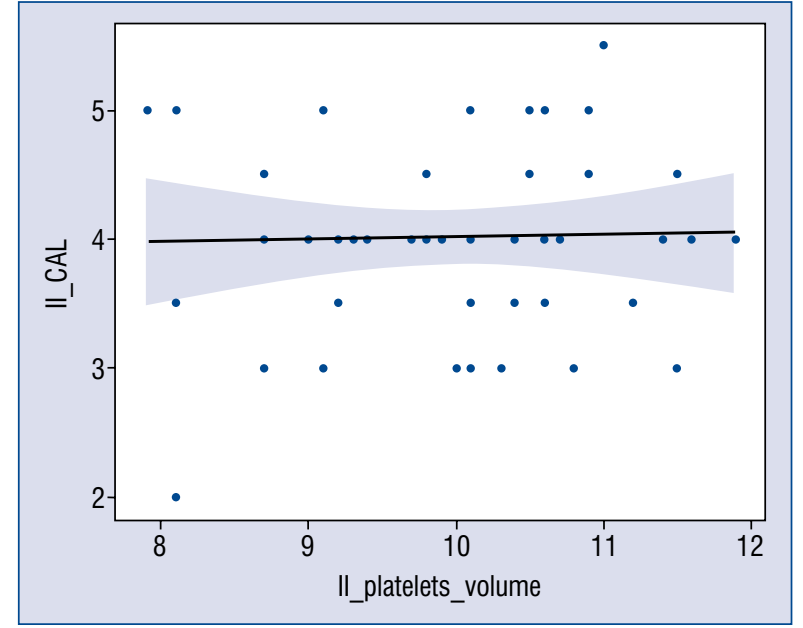

Figure 3. The values of mean platelet volume (MPV) vs. clinical attachment loss $(\mathrm{CAL} / \mathrm{mm})$ after periodontal intervention (MPV \pm SD 0.98; CAL/mm \pm SD 0.80); $\mathrm{SD}$ - standard deviation.

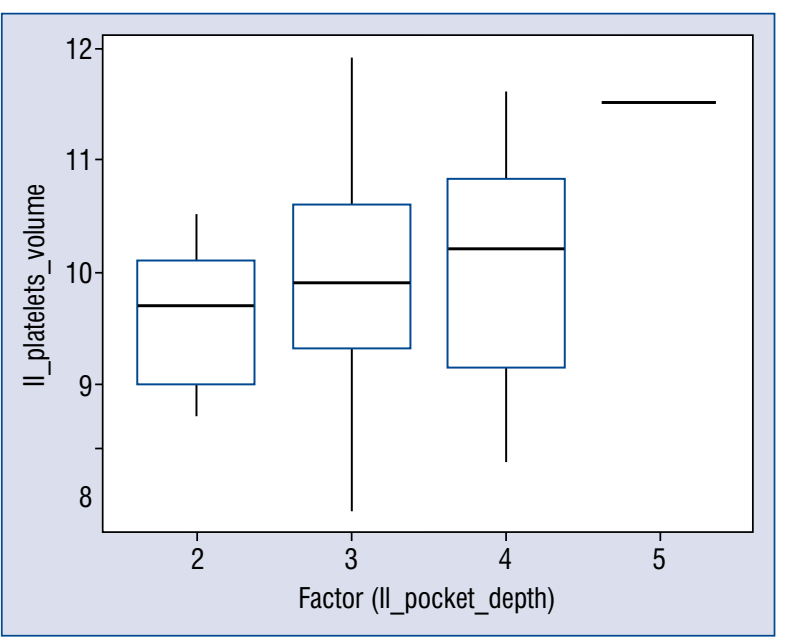

Figure 4. The values of mean platelet volume (MPV) vs. probing depth $(\mathrm{PD} / \mathrm{mm})$ after periodontal intervention (MPV \pm SD 0.98; PD/mm \pm SD 0.74); SD — standard deviation.

was observed. It is therefore justified that the change of CAL value has influenced an increased MPV distribution.

\section{B.IV. MPV change vs. PD/mm change}

Correlation between $\mathrm{PD} / \mathrm{mm}$ parameter change before and after periodontal intervention and MPV was tested. $\mathrm{PD} / \mathrm{mm}$ value changes are subtle, and importantly values 1 and 4 are scarce and will not be further analyzed. The following results were obtained: statistical value W: 0.3694; p: 0.5462 (Fig. 6). 


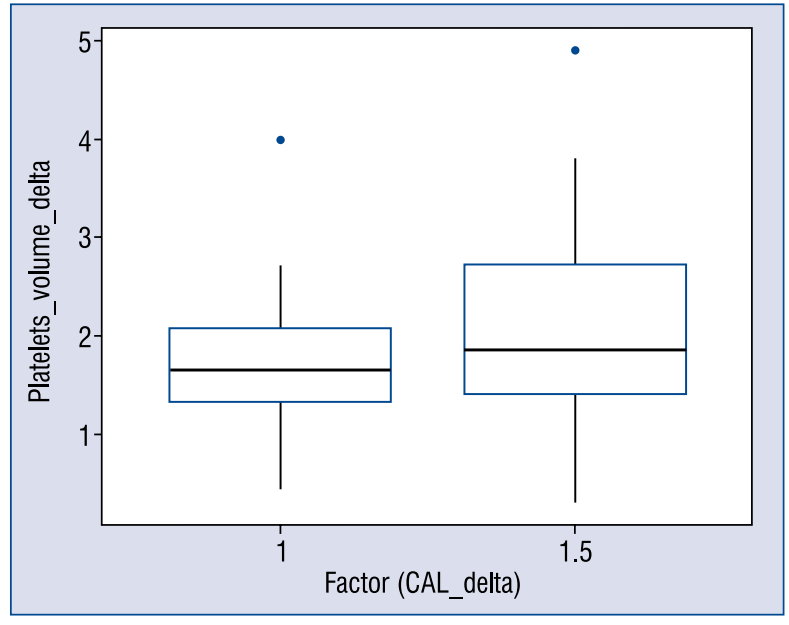

Figure 5. The values of $\Delta$ mean platelet volume ( $\triangle \mathrm{MPV}$ ) vs. $\Delta$ clinical attachment loss $(\triangle \mathrm{CAL} / \mathrm{mm})$ during experiment observation ( $\triangle \mathrm{MPV} \pm \mathrm{SD} 14.58 ; \Delta \mathrm{CAL} / \mathrm{mm} \pm \mathrm{SD} 53.51$ ); SD - standard deviation.

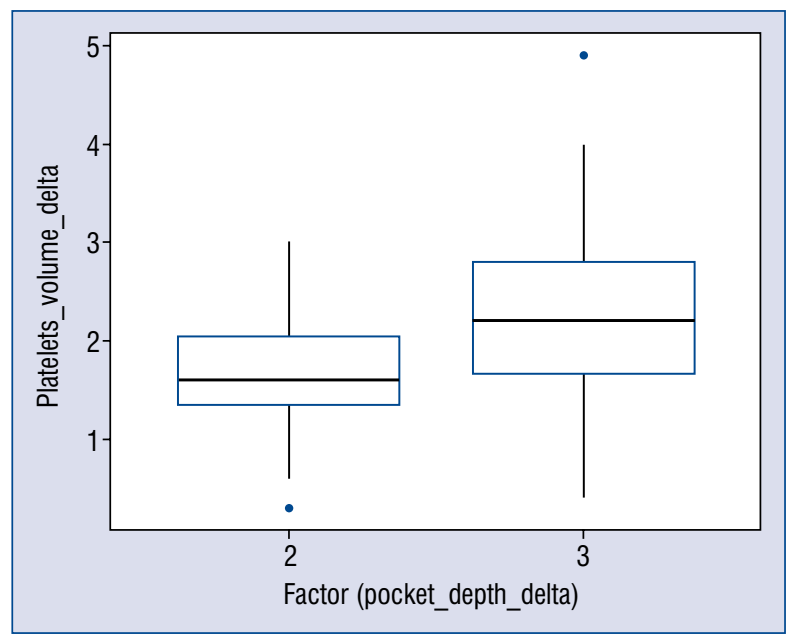

Figure 6. The values of $\Delta$ mean platelet volume ( $\triangle \mathrm{MPV})$ change vs. $\Delta$ probing depth $(\triangle \mathrm{PD} / \mathrm{mm})$ during experiment observation ( $\Delta \mathrm{MPV} \pm \mathrm{SD} 14.58 ; \Delta \mathrm{PD} / \mathrm{mm} \pm \mathrm{SD} 7.42$ ); $\mathrm{SD}$ - standard deviation.

There is positive relationship between $\mathrm{PD} / \mathrm{mm}$ change and MPV change. $\mathrm{PD} / \mathrm{mm}$ value change after value 1 and 4 were deleted is shown on the box plot. For larger $\mathrm{PD} / \mathrm{mm}$ value changes increased MPV value change occurred. The test has shown a statistically significant difference of $5 \%$.

Periodontal assessment was performed after PDe treatment (the so called periodontal intervention) was completed. The number of patients remained constant during whole study. API values decreased to $28 \%$ among women and $30 \%$ among men. BOP also significantly decreased to $36 \%$ in women group and $41 \%$ in men. Both gender groups resulted in $\mathrm{CAL} / \mathrm{mm}$ value $4.0 \mathrm{~mm}$ and $\mathrm{PD} / \mathrm{mm}$ $3.3 \mathrm{~mm}$. After oral cavity sanitation, the average number of remaining teeth in women was 10 for maxilla and 9 for mandible, among men 9 and 8 , respectively.

\section{Discussion}

Fifty patients $\leq 92$ years (age: $36-92$; mean age: 64 years) with $\mathrm{CHF}$ and $\mathrm{PD}$ diagnosis were enrolled into this pilot study. It was found that MPV measurements on admission day as well as clinical periodontal assessment (examination-1) are different from results obtained after standard periodontal treatment (examination-2). S A statistically significant decrease of PD value over a of mean of a 6 month observation period (3-9 months) was noted.

In addition to a decrease of $\mathrm{BOP}$ and $\mathrm{PI}$ values in all study patients, mean increase in $\mathrm{CAL} / \mathrm{mm}$ values of $1.5 \mathrm{~mm}$ was noted showing advantage of restoration over destruction processes within alveolar bone of maxilla and mandible. It should be noted that no highly specialized Guided Bone Regeneration (GBR) and/or Guided Tissue Regeneration (GTR) procedures were performed, justifying potential likelihood of including this type of therapy into CHF treatment standard.

Significant correlation between a decrease of clinical $\mathrm{PD} / \mathrm{mm}$ values and increased MPV value change and decrease should be noted. Statistical analysis has shown that the decrease in $\mathrm{PD} / \mathrm{mm}$ value which is much easier to obtain by basic dental care, has resulted in better effects in study group patients than $\mathrm{CAL} / \mathrm{mm}$ decrease that can be mainly obtained only by highly specialized, expensive periodontal procedures.

In this pilot study group during a 6-month observation no signs of heart failure exacerbation were observed, and pharmacological therapy that was in accordance with current CHF treatment guidelines, required no modifications of each medicament dose and type (Tables 1 and 2).

Authors of this paper have focused their research on the relationship between PDe and heart disease. Current studies and observations as well as published results referred patients who were hospitalized due to acute coronary syndromes [11-15, 27]. Results of this pilot study have shown that proper and complex oral hygiene may influence blood serum levels of CRP, NT-proBNP and TNF- $\alpha$ which are all markers of inflammation [18, 28-32]. Individualized patterns of CHF patient 
Table 1. Clinical characteristics of study population.

\begin{tabular}{lccccccc}
\hline Gender & $\begin{array}{c}\text { Age } \\
\text { (av.) }\end{array}$ & $\begin{array}{c}\text { NYHA class/ } \\
\text { /mean EF }\end{array}$ & $\begin{array}{c}\text { Myocardial } \\
\text { infarction }\end{array}$ & Hypertension & CAD & Dislipidemia & Diabetes \\
\hline Women $(n=15)$ & 64 & II-III/38 $\pm 9 \%$ & $8(53 \%)$ & $13(87 \%)$ & $8(53 \%)$ & $7(47 \%)$ & 2 \\
Men $(n=35)$ & 63 & II-IV/38 $\pm 11 \%$ & $21(60 \%)$ & $32(91 \%)$ & $27(77 \%)$ & $18(51 \%)$ & 4 \\
\hline
\end{tabular}

CAD - coronary artery disease; EF — ejection fraction; NYHA — New York Heart Association

Table 2. Pharmacological treatment.

\begin{tabular}{lccccc}
\hline Gender & ACEI, sartans & Beta-antagonists & Aldosterone antagonists & ICD/CRT & Statins \\
\hline Women $(n=15)$ & $100 \%$ & $100 \%$ & $93 \%$ & $13 \%$ & $80 \%$ \\
Men $(n=35)$ & $100 \%$ & $100 \%$ & $94 \%$ & $11 \%$ & $80 \%$ \\
\hline
\end{tabular}

ACEI — angiotensyn convering enzyme inhibitors; CRT — cardiac resynchronization therapy; ICD — implantable cardioverter-defibrillator

care, seems obvious and also results in prognosis improvement, increased treatment efficacy and patient comfort [33-35].

\section{Limitations of the study}

The main limitation of the study was the small group of patients included. Secondly, was the absence of a control group. However, it is very difficult to create such a control group for two reasons. One - patients could not be found with $\mathrm{CHF}$ and a healthy peridontium in among the general population. Secondly, it would be ethically controversial to treat PDe only in a subgroup of patients. Therefore, after taking into consideration the Ethics Committee opinion on this study, we have decided to perform it in this form and call it a pilot study.

\section{Conclusions}

Results of this pilot study should be verified in a larger patient cohort. The results of this study show that:

- decreases of $\mathrm{PD} / \mathrm{mm}$ results in significantly better results of MPV $(\mathrm{p}=0.05)$ than reduction of $\mathrm{CAL} / \mathrm{mm}$ value;

- specialist periodontal treatment may result in decreased MPV value in patients with coexistent CHF and PDe;

- examed platelet parameter may have prognostic value in $\mathrm{CHF}$, periodontal treatment of $\mathrm{CHF}$ and PDe patients might improve their long-term prognosis, but it ought to be verified in a prospective study;
- the above conclusions are, to the authors' best knowledge, first published conclusions in this area and require verification on a larger patient population.

Funding: This research study was funded by the National Science Center (N N403 218139).

Conflict of interest: None declared

\section{References}

1. Karataş MB, Çanga Y, İpek G, et al. Association of admission serum laboratory parameters with new-onset atrial fibrillation after a primary percutaneous coronary intervention. Coron Artery Dis. 2016; 27(2): 128-134, doi: 10.1097/MCA.0000000000000333, indexed in Pubmed: 26693808.

2. Bolat I, Akgul O, Cakmak HA, et al. The prognostic value of admission mean platelet volume to platelet count ratio in patients with ST-segment elevation myocardial infarction undergoing primary percutaneous coronary intervention. Kardiol Pol. 2016; 74(4): 346-355, doi:10.5603/KP.a2015.0179, indexed in Pubmed: 26365942.

3. Sansanayudh N, Numthavaj P, Muntham D, et al. Prognostic effect of mean platelet volume in patients with coronary artery disease. A systematic review and meta-analysis. Thromb Haemost. 2015; 114(6): 1299-1309, doi: 10.1160/TH15-04-0280, indexed in Pubmed: 26245769.

4. Yılmaz F, Köklü E, Kizilirmak Yilmaz F, et al. Evaluation of mean platelet volume and platelet distribution width in patients with asymptomatic intermediate carotid artery plaque. Kardiol Pol. 2017; 75(1): 35-41, doi: 10.5603/KP.a2016.0129, indexed in Pubmed: 27714714.

5. İleri M, Kanat S, Gürsoy HT, et al. Increased mean platelet volume in rheumatic mitral stenosis: assessment of clinical and echocardiographic determinants. Kardiol Pol. 2015; 73(1): 46-53, doi: 10.5603/KP.a2014.0115, indexed in Pubmed: 24846369. 
6. $\quad$ Łysek R, Szafraniec K, Polak M, et al. Relationship between past myocardial infarction, periodontal disease and Porphyromonas gingivalis serum antibodies: A case-control study. Cardiol J. 2018; 25(3): 386-392, doi: 10.5603/cj.a2017.0015.

7. Wożakowska-Kapłon B, Włosowicz M, Gorczyca-Michta I, et al. Oral health status and the occurrence and clinical course of myocardial infarction in hospital phase: a case-control study. Cardiol J. 2013; 20(4): 370-377, doi: 10.5603/CJ.2013.0095, indexed in Pubmed: 23913455.

8. Androsz-Kowalska O, Jankowski K, Rymarczyk Z, et al. Correlation between clinical parameters of periodontal disease and mean platelet volume in patients with coronary artery disease: a pilot study. Kardiol Pol. 2013; 71(6): 600-605, doi: 10.5603/ KP.2013.0124, indexed in Pubmed: 23797433.

9. Kandis H, Ozhan H, Ordu S, et al. The prognostic value of mean platelet volume in decompensated heart failure. Emerg Med J. 2011; 28(7): 575-578, doi: 10.1136/emj.2009.088401, indexed in Pubmed: 20660896.

10. Budak YU, Huysal K, Demirci H. Correlation between mean platelet volume and B-type natriuretic peptide concentration in emergency patients with heart failure. Biochem Med (Zagreb). 2015; 25(1): 97-102, doi: 10.11613/BM.2015.012, indexed in Pubmed: 25672473.

11. Czerniuk M, Filipiak KJ, Górska R, et al. [Periodontal state and cardiovascular diseases]. Pol Arch Med Wewn. 1999; 101(5): 433-436, indexed in Pubmed: 10740424.

12. Czerniuk MR, Górska R, Filipiak KJ, et al. Inflammatory response to acute coronary syndrome in patients with coexistent periodontal disease. J Periodontol. 2004; 75(7): 1020-1026, doi: 10.1902/jop.2004.75.7.1020, indexed in Pubmed: 15341362.

13. Czerniuk MR, Górska R, Filipiak KJ, et al. C-reactive protein in patients with coexistent periodontal disease and acute coronary syndromes. J Clin Periodontol. 2006; 33(6): 415-420, doi: 10.1111/j.1600-051X.2006.00931.x, indexed in Pubmed: 16677330.

14. Zaremba M, Górska R, Suwalski P, et al. Periodontitis as a risk factor of coronary heart diseases? Adv Med Sci. 2006; 51 Suppl 1: 34-39, indexed in Pubmed: 17458056.

15. Czerniuk MR, Gorska R, Filipiak KJ, et al. The influence of periodontal diseases on intensivity and dynamice of inflammation response in patients with acute coronary syndromes. Dent Med Probl. 2002; 39(1): 31-37.

16. Czerniuk MR, Eickholz P, Grötz KA. Oral cavity infections: why should cardiologists care about them? Kardiol Pol. 2015; 73(10): 901-908, doi:10.5603/KP.2015.0188, indexed in Pubmed: 26521837.

17. Czerniuk M, Bartoszewicz Z, Filipiak K, et al. Osoczowe stężenia NT-proBNP u pacjentów z niewydolnością serca i wspólistniejącą chorobą przyzębia: badania pilotażowe. Kardiol Pol. 2017; 75(2): 135-142, doi: 10.5603/kp.a2016.0148.

18. Saffi MA, Furtado MV, Polanczyk CA, et al. Relationship between vascular endothelium and periodontal disease in atherosclerotic lesions: Review article. World J Cardiol. 2015; 7(1): 26-30, doi: 10.4330/wjc.v7.i1.26, indexed in Pubmed: 25632316.

19. Pearson TA, Mensah GA, Alexander RW, et al. Markers of inflammation and cardiovascular disease: application to clinical and public health practice: A statement for healthcare professionals from the Centers for Disease Control and Prevention and the American Heart Association. Circulation. 2003; 107(3): 499-511, indexed in Pubmed: 12551878.
20. D’Aiuto F, Parkar M, Andreou G, et al. Periodontitis and systemic inflammation: control of the local infection is associated with a reduction in serum inflammatory markers. J Dent Res. 2004; 83(2): 156-160, doi: 10.1177/154405910408300214, indexed in Pubmed: 14742655.

21. Higashi Y, Noma K, Yoshizumi M, et al. Endothelial function and oxidative stress in cardiovascular diseases. Circ J. 2009; 73(3): 411-418, indexed in Pubmed: 19194043.

22. de Araújo Júnior RF, Souza TO, de Medeiros CA, et al. Carvedilol decrease IL- $1 \beta$ and TNF- $\alpha$, inhibits MMP-2, MMP-9, COX-2, and RANKL expression, and up-regulates OPG in a rat model of periodontitis. PLoS One. 2013; 8(7): e66391, doi: 10.1371/journal. pone.0066391, indexed in Pubmed:23843954.

23. Lange DE, Plagman HC, Eenboom A, et al. Klinische Bewertungsverfaren zur Obiekitiverung der Mundhygiene. Dtsch Zahnarztl Z. 1977; 32: 44-47.

24. Hall WB. Critical Decisions in Periodontology. Fourth Edition, BC Decker Inc, Hamilton, London 2003: 30-31.

25. Hall WB. Clinical Practice. In: Steele PF (ed). Dimensions of Dental Hygiene. Third Edition. Lea\&Febiger, Philiadelphia 1982: 153.

26. Dibart S, Dietrich T. Practical periodontal diagnostic and treatment planning. Chapter 2. Wiley-Blackwell, Iowa 2010.

27. Kaisare S, Rao J, Dubashi N. Periodontal disease as a risk factor for acute myocardial infarction. A case-control study in Goans highlighting a review of the literature. Br Dent J. 2007; 203(3): 144-145, doi: 10.1038/bdj.2007.690, indexed in Pubmed: 17694042.

28. Ximénez-Fyvie LA, Haffajee AD, Socransky SS. Comparison of the microbiota of supra- and subgingival plaque in health and periodontitis. J Clin Periodontol. 2000; 27(9): 648-657, indexed in Pubmed: 10983598.

29. Dorn JM, Genco RJ, Grossi SG, et al. Periodontal disease and recurrent cardiovascular events in survivors of myocardial infarction (MI): the Western New York Acute MI Study. J Periodontol. 2010; 81(4): 502-511, doi: 10.1902/jop.2009.090499, indexed in Pubmed: 20367093.

30. Blair FM, Chapple ILC. Prescribing for periodontal disease. Prim Dent J. 2014; 3(4): 38-43, doi: 10.1308/205016814813877234, indexed in Pubmed:25668374.

31. Chukkapalli SS, Velsko IM, Rivera-Kweh MF, et al. Polymicrobial oral infection with four periodontal bacteria orchestrates a distinct inflammatory response and atherosclerosis in apoe null mice. PLoS One. 2015; 10(11): e0143291, doi: 10.1371/journal. pone.0143291, indexed in Pubmed:26619277.

32. Beck JD, Eke P, Heiss G, et al. Periodontal disease and coronary heart disease: a reappraisal of the exposure. Circulation. 2005; 112(1): 19-24, doi:10.1161/CIRCULATIONAHA.104.511998, indexed in Pubmed: 15983248.

33. Tonetti MS, Eickholz P, Loos BG, et al. Principles in prevention of periodontal diseases: Consensus report of group 1 of the 11(th) European Workshop on Periodontology on effective prevention of periodontal and peri-implant diseases. J Clin Periodontol. 2015; 42(Suppl 16): 5-11.

34. Seymour RA. Is gum disease killing your patient? Br Dent J. 2009; 206(10): 551-552, doi: 10.1038/sj.bdj.2009.472, indexed in Pubmed: 19461642.

35. Meyer-Bäumer A, Eick S, Mertens C, et al. Periodontal pathogens and associated factors in aggressive periodontitis: results 5-17 years after active periodontal therapy. J Clin Periodontol. 2014; 41(7): 662-672, doi: 10.1111/jcpe.12255, indexed in Pubmed: 24708362. 